\title{
Professional Doctorate
}

National Cancer Institute

\section{Source}

National Cancer Institute. Professional Doctorate. NCI Thesaurus. Code C67143.

A doctorate awarded in certain fields where most holders of the degree are not engaged primarily in scholarly research and academic activities, but rather in a profession, such as law, medicine, music, or ministry. 